\title{
Physiotherapists as supplementary prescribers: Opinion of Nigerian doctors
}

\author{
Onigbinde Ayodele Teslim ${ }^{1, ~ *, ~ O y e n i r a n ~ T o l u l o p e ~ O l a o l u w a ~}{ }^{1}$, Mukoka Grace², \\ Nondwe Bongokazi Mlenzana ${ }^{3}$, Manie Shamilar $^{4}$, Tarimo Nesto ${ }^{5}$ \\ ${ }^{1}$ Department of Medical Rehabilitation, College of Health Sciences, Obafemi Awolowo University, Ile-Ife, Osun State, Nigeria \\ ${ }^{2}$ Department of Physiotherapy, College of Medicine, University of Malawi, Blantyre, Malawi \\ ${ }^{3}$ Department of physiotherapy, University of Western Cape, Bellville, South Africa \\ ${ }^{4}$ Department of Health and Rehabilitation science, Faculty of Health Sciences, University Cape town, Cape town, South Africa \\ ${ }^{5}$ Physiotherapy department, Malawi Against Physical disabilities, P. O. Box 256, Blantyre, Malawi
}

\section{Email address:}

ayotesonigbinde@yahoo.co.uk (A. T. Onigbinde)

\section{To cite this article:}

Onigbinde Ayodele Teslim, Oyeniran Tolulope Olaoluwa, Mukoka Grace, Nondwe Bongokazi Mlenzana, Manie Shamilar, Tarimo Nesto. Physiotherapists as Supplementary Prescribers: Opinion of Nigerian Doctors. American Journal of Health Research. Special Issue: Supplementary Prescribing in Nigeria: A Needy Concept to Promote Clinical Physiotherapy Practice. Vol. 2, No. 5-1, 2014, pp. $12-16$. doi: $10.11648 /$ j.ajhr.s.2014020501.13

\begin{abstract}
In Nigeria, doctors have the sole primary responsibility of prescribing medications for patients, contrarily, in the United Kingdom (UK), physiotherapists have advanced from being supplementary prescribers in 2005 to independent prescribers in 2012; and this was aimed at improving patient's accessibility to medications. The primary aim of this study was to investigate the opinion of Nigerian medical doctors on physiotherapists assuming the roles of supplementary prescribers. A self-administered questionnaire was used to seek opinion of 372 medical doctors in purposively selected hospitals. Descriptive statistics of frequency, percentages, mean, standard deviation and chi-square were used to analyze the data. Two hundred and twenty-two doctors $(59.7 \%)$ were unaware that physiotherapists are supplementary prescribers in UK. The number of respondents $(55.1 \%)$ who objected to physiotherapists becoming supplementary prescribers was significantly higher than those who supported it $\left(\mathrm{X}^{2}-3.88, \mathrm{p}=0.05\right)$. Amongst to that supported supplementary $(44.9 \%)$ prescription for physiotherapists, $98.2 \%, 72.5 \%$ and $58.7 \%$ opined that physiotherapists should be allowed prescribe analgesics, NSAIDs and muscle relaxants respectively. Only 4 doctors $(1.1 \%)$ supported the prescription of anti-hypertensive drugs. We concluded that most medical doctors are unaware that physiotherapists as supplementary prescribers in UK and majority of them objected to Nigerian physiotherapists being recognized as supplementary prescribers.
\end{abstract}

Keywords: Supplementary Prescribers, Physiotherapists, Doctors, Nigeria, Medications

\section{Introduction}

The first major step of improving effective health care services is an inter-professional understanding of other member's unique role and contributions with patients' interest upper most. Each provider should be aware and knowledgeable of the skills of the other members [1]. Physiotherapy is a dynamic profession and the scope of practice is expanding, especially in United Kingdom. The Crown report in United Kingdom (UK) recommended that specialist physiotherapists be extended prescribing rights [2]. Hence, physiotherapists in the UK were legislated to be supplementary prescribers in 2003 and in 2013 they were elevated to independent prescription status [3]. This is currently posing challenges to the dominance of medical doctors who have the primary authority to prescribe medicines in Britain [4], [5]. Although, the primary responsibilities of doctors to assess and diagnose clinical conditions; decide clinical management plans and prescribe as appropriate is still intact.

The supplementary prescriber will be responsible for the continuing care of patients who have been clinically assessed by an independent prescriber and this is after a clinical management plan has been developed in conjunction with the patient [6]. Supplementary prescribing has given doctors in UK opportunity to concentrate on critically ill patients who 
require urgent acute medical attention [6,7]. There are currently no legal restrictions on the clinical conditions which supplementary prescribers may treat [8]. Chartered Society of Physiotherapy believed that supplementary prescription has been beneficial to patients through timely use of medications and cost-effective services [7].

In Nigeria, most physiotherapists are involved in Homebased Rehabilitation and this gives them opportunity to have regular contact with patients [9]. These patients require medications but they have no opportunity to regularly review the drugs as a result of poor accessibility to doctors and standard hospitals at the urban areas. Also, there is a poor geographical distribution of health care professionals and this contributed largely to dearth in manpower of doctors [10]. Subsequently, patients expected physiotherapists to review their medications.

We are currently unaware of the position of Nigerian doctors on the clamour for change in the role of physiotherapists in drug prescription. Australian physicians rejected the growing trend of granting prescribing rights to non-medical health professionals, with the exception of dentists [11]. It is being speculated that Nigerian Medical Association may also oppose the granting of prescription rights to Nigerian physiotherapists. However, there is a paucity of data on the opinion of Nigerian doctors on supplementary prescription. The primary aim of this study was to investigate the opinion of medical doctors on the enlistment of Nigerian physiotherapists as supplementary prescribers.

\section{Materials and Method}

\subsection{Study Settings}

The doctors were drawn from 4 University Teaching Hospitals, 1 Federal Medical Centres, 2 state hospitals and 1 private hospital.

\subsection{Sample}

The sample comprised 372 practicing doctors in purposively selected hospitals. The major inclusive criteria are that the doctors must be licensed to practice in Nigeria and must have at least one year experience. Those that were not willing to answer the questionnaire immediately were excluded from the study.

\subsection{Sampling Technique}

The doctors were sample of convenience.

\subsection{Research Design}

This study was a quantitative cross sectional survey.

\subsection{Instrument}

The instrument used in obtaining information for this study was a modification of a self-administered questionnaire used by Onigbinde et al [12]. This questionnaire took into account the demographic details of the subjects, opinion and attitude towards prescription of relevant medications by physiotherapists. The questions were made simple and unambiguous for easy understanding. A draft of the questionnaire was pilot tested among five doctors who were exempted from the main study. They were implored to review and assess the content of the questionnaire for accuracy, precision and to determine the appropriateness of the questions for the objectives of the study. Changes were made based on their corrections and advice. The revised version of the questionnaire was used for data collection.

\subsection{Procedure}

Ethical approval was granted by the Research and Ethics Committee of the Institute of Public Health, Obafemi Awolowo University, Ile-Ife, Osun State, Nigeria (IPH/OAU/12/154). Also, permission was granted by the Heads of departments of the study settings. The copies of questionnaire were administered to the subjects and in order to maintain anonymity, subjects' name and address were not requested for in the questionnaire. Section A of the questionnaire requested for the demographic and academic related data, section $B$ was used to determine the current awareness of medical doctors on supplementary prescription. Section $\mathrm{C}$ was used to determine the perception of medical doctors on which sources would improve the pharmacological knowledge of physiotherapists while section $\mathrm{D}$ was used to assess the opinion of medical doctors on reasons for changing prescription status of physiotherapists. There was no time limit for the completion of the questionnaire.

\subsection{Data Analysis}

The copies of questionnaire were collated and entered into Statistical Package for Social Sciences (SPSS) software version 17 of a password protected computer, which only member of the research team had access to. A descriptive statistics (frequency, percentages, mean and standard deviation) were used to analyze the data.

The non-parametric statistics (chi-square test of Association) was used to determine association between years of experience and frequency of respondents who supported enlistment of physiotherapists as supplementary prescribers. Also, chi-square was used to compare the number of respondents who chose options of yes and no to each opinion.

\section{Results}

There are $279(75 \%)$ male and 93 (25\%) female doctors. The demographic data, qualifications, study settings and years of clinical experience are presented in Table 1. The majority, $222(59.7 \%)$ of medical doctors are unaware that physiotherapists are supplementary prescribers in UK. Also, $205(55.1 \%)$ objected to changing the prescription status of physiotherapists in Nigeria to that of supplementary 
prescribers. The number of respondents who objected was significantly higher than those who supported it $\left(\mathrm{X}^{2}-3.88, \mathrm{P}\right.$ $=0.05)$. However, there was no significant association between years of experience and the frequency of respondents who supported enlistment of physiotherapists as supplementary prescribers (Table 2).

Among 167 that supported change in prescription status, 164 (98.2\%), 98 (58.7\%) and 121 (72.5\%) doctors opined that physiotherapists could prescribe analgesics, muscle relaxants and NSAIDs respectively. Responses on other classes of drugs are represented in figure 1 . The majority of doctors $[272(73.1 \%)]$ and $188(50.5 \%)$ opined that reviewing current school curricular and continuing professional development programmes respectively might improve the pharmacological knowledge of physiotherapists. Responses on other sources of acquiring improvements are in Table 3. Furthermore, 137 (36.8\%) doctors opined that patients would benefit from a combination of medications and physiotherapy and $121 \quad(32.5 \%)$ opined that physiotherapists would be relevant as supplementary prescribers for certain chronic conditions. Very few respondents $[42(11.3 \%)]$ reported that it would be cost effective while only $22(5.9 \%)$ opined that drug alone would be effective. Responses on other reasons why prescription status should change are in Table 4.

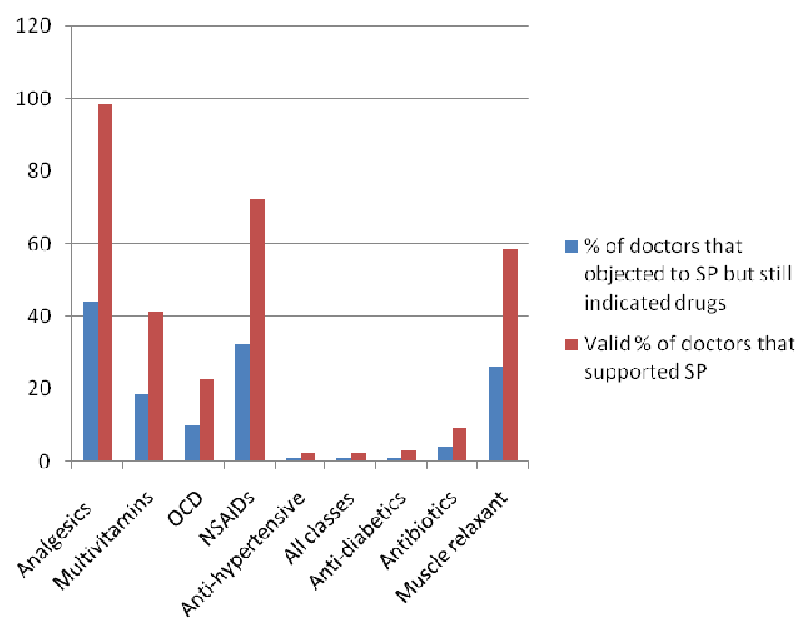

Key: OCD- Over the counter drugs

Figure 1. Opinion on the classes of drugs physiotherapists should prescribe (Multiple Choice Questions)

\section{Discussion}

Supplementary prescription is a policy that had been reported to meet the desired goal of achieving modern day health care services [4]. In the UK, it is a positive development in modern day health care but it requires educational training for allied health professionals because some were perceived to lack adequate pharmacology knowledge, counseling and clinical diagnostic skills while the doctors retain the responsibilities of ensuring patient's safety under the supplementary prescription policy [3].

A significant proportion of the doctors objected to changing the prescription status of physiotherapists to supplementary prescribing. In the UK, Crown report recommended that specialist physiotherapists should be extended prescription rights [13]. Our current finding showed that more than half of respondents were unaware that specialist physiotherapists are supplementary prescribers in UK; suggesting that there might be opposition from doctors towards enlisting physiotherapists as SPs in Nigeria. This objection might be attributed to their lack of awareness about the roles and effectiveness of physiotherapists in supplementary prescribing outside Nigeria. In health care services, learning about other professions is the first step towards achieving the desired goals but many professionals are remarkably unaware of developments and scope of practice of others [1].

Table 1. Respondents $\backslash$ Demographics and Academics Related Data

\begin{tabular}{llll}
\hline Variables & & Frequency & Percentage\% \\
\hline \multirow{2}{*}{ Gender: } & Male & 279 & 75 \\
& Female & 93 & 25 \\
& MBBS & 151 & 40.6 \\
& Masters & 10 & 2.7 \\
Qualifications: & Phd & 1 & 0.3 \\
& Resident doctor & 191 & 51.3 \\
& Fellow & 19 & 5.1 \\
& Teaching Hospital & 294 & 79.0 \\
& State Hospital & 38 & 10.2 \\
Work Settings : & Private Hospital & 3 & 0.8 \\
& Academics & 4 & 1.1 \\
& Others & 33 & 8.9 \\
\hline
\end{tabular}

Table 2. Awareness and change of prescription status to supplementary prescribing

\begin{tabular}{llllll}
\hline Variables & & Frequency & Percentage (\%) & $\mathbf{X}^{\mathbf{2}}$ & $\mathbf{P}$ \\
\hline Awareness & Yes & 149 & 40.1 & & \\
& No & 222 & 59.7 & & \\
Change status: & Yes & 167 & 44.9 & & \\
& No & 205 & 55.1 & 3.88 & 0.05 \\
\hline
\end{tabular}

Table 3. Opinion on sources that can improve physiotherapists' pharmacological knowledge (Multiple choice questions)

\begin{tabular}{lll}
\hline Variables & Frequency & Percentage (\%) \\
\hline Current School Training & 157 & 42.2 \\
Reviewing School Curricular & 272 & 73.1 \\
DPT & 77 & 20.7 \\
Seminar \& Workshop & 151 & 40.6 \\
Transitional DPT & 43 & 11.6 \\
Professional development & 188 & 50.5 \\
\hline
\end{tabular}

In UK, Bissell et al had earlier reported that doctors and patients were perceived to lack awareness of supplementary prescribing [3]. A similar trend was observed among members of Australian medical association in 2012 when Australian physicians rejected the growing trend of granting prescribing rights to non-medical health professionals [11].

Amongst doctors that supported supplementary prescription roles for Nigerian physiotherapists, almost all respondents opined that physiotherapists should be allowed 
to prescribe analgesics and NSAIDS while more than half of them supported prescription of muscle relaxants. Moore et al and Grimmer et al reported that the most recommended medications for musculoskeletal dysfunctions by physiotherapists in Australia are NSAIDs [14,15]. The support for prescribing muscle relaxant may be attributed to the recognized role physiotherapists play in management of spasticity experienced by stroke survivours and spinal cord injured patients.

Almost all respondents did not support prescription of antihypertensive, anti-diabetics and OTC drugs. We felt the doctors in this study were biased. They still objected to prescription of common OTC drugs which non-health professionals can purchase without prescription. Lansbury and Sullivan observed that physiotherapists frequently advise and prescribe over the counter (OTC) medications to their patients [16]. In Nigeria, during home rehabilitation, most patients rely on physiotherapists to give advice or prescribe medications especially anti-hypertensive, muscle relaxant and OTC (Over-The-Counter) drugs as they may be without timely access to review of medications by doctors. Chartered Society of Physiotherapists reported that restriction in prescription by physiotherapists would not be desirable for effective rehabilitation programme [7].

Table 4. Opinion on benefits and relevance of changing prescription status (Multiple Choice Questions)

\begin{tabular}{llll}
\hline Variables & Frequency & Percentage (\%) \\
\hline Benefits: Improvement in patient's care & 108 & 29.0 & Valid percentage (\%) \\
Benefits from combined therapy & 137 & 36.8 & 64.7 \\
Reduced doctor's Load & 79 & 21.2 & 22.0 \\
Management more accessible & 82 & 14.5 & 47.3 \\
Doctors concentrate on critical illness & 54 & 11.3 & 21.5 \\
Cost effectiveness & 42 & 5.9 & 32.3 \\
Physiotherapy alone is inadequate & 80 & 21.8 & 25.2 \\
Drug alone is effective & 22 & 14.5 & 47.9 \\
Reduces patient's Waiting time & 81 & 32.5 \\
Increase confidence in physiotherapy & 54 & 14.2 \\
Relevance: Chronic conditions & 121 & 48.5 \\
Acute conditions & 53 & 32.3 \\
\hline
\end{tabular}

$* \%$ based on the frequency of those that supported change in prescription status

A large number of doctors among those that supported prescribing role for physiotherapist opined that physiotherapists would be relevant in chronic conditions and that there would be improvement in patient's care and effective clinical practice if physiotherapists are SPs. However, almost all the doctors supported multi-disciplinary approach and also recognized the different goals of individual team members as they opined that medications alone would not be effective for patients.

Reviewing current school curricular was the major source identified by the doctors as a means of improving physiotherapists' pharmacological knowledge and this was similar to the opinion shared by physiotherapists [12]. The Nigeria society of physiotherapy will have to provide opportunity for the training of specialists with interest in pharmacophysiotherapy and who will be willing to be supplementary subscribers. The current pharmacology undergraduate physiotherapy training in Nigeria may not be sufficient to assume the position of SP [12].

The major reasons given by CSP in UK and also previous reports were that supplementary prescription would reduce waiting time of patients, burden on doctors, be cost effective and would give opportunity for doctors to concentrate on critically ill patients $[3,4,12,17]$. However very few doctors $(11.3 \%-22.0 \%)$ in this study shared similar opinion. We considered these opinions to be deficient for Nigeria to meet the required modern day health care policy. The doctorpatient ratio in Nigeria was 1:6400 as against the World Health Organization (WHO) standard of 1:600 and this remains a huge challenge despite graduating between 2,500 and 4,000 new doctors annually [10]. Most Nigerian doctors are working in the United States, Britain, South Africa, and other neighbouring African countries because of poor working conditions. In 2013 there are only 25, 000 doctors in the country out of 65, 000 registered by Nigerian Medical Council [10]. These showed that Nigerian doctors are being overworked and there may be difficulties for patients to have accessibility to them for prompt and adequate medical interventions

We concluded that most medical doctors were unaware of the prescription status of physiotherapists as supplementary prescribers in UK. Also, Nigerian doctors objected to granting supplementary prescription rights to physiotherapists, although, majority opined that if current school curricular were reviewed, it would improve pharmacological knowledge of physiotherapists.

\section{References}

[1] Grant RW, Finnocchio LJ and the California Primary Care Consortium Subcommittee on Interdisciplinary Collaboration. (1995). Common barriers to interprofessional healthcare team work. https://www.med.mun.ca/ Common-barriers-tointerprofessional-healthcare-te.aspx. Accessed on $16^{\text {th }}$ June 2014.

[2] Physioped (2012). Prescribing Rights in the UK. http://www.physio-pedia.com/Prescribing_Rights_in_the_UK. Accessed on 19th June 2014. 
[3] Bissel Paul, Richard Cooper, Louise Guillaume, Claire Anderson, Anthony Avery, Allen Hutchinson, Veronica James, Joanne Lymn, Elizabeth Murphy, Julie Ratcliffe, Paul Ward, Ian Woosley (2008); An Evaluation of Supplementary Prescribing in Nursing and Pharmacy. Final report of Department of Health, The University of Shefield, eprint@whiterose.ac.uk. Accessed on the $19^{\text {th }}$ June 2014.

[4] Cooper R, Anderson C, Avery T, Bissell P, Guillaume L, Hutchinson A, Lymn J, Murphy E, Ratcliffe J, Ward P. J (2008). Nurse and pharmacists supplementary prescribing in the UK. A thematic review of the literature. Health policy, 85, $277-292$.

[5] Pharmaceutical Services Negotiating Committee (PNSC) (2012). www.pnsc. org.uk/pages/pharmacy. Accessed on 10th January 2014.

[6] Crown report (2000). Proposed quality framework for extension of prescribing; recommendation 3 , chapter 6 , pg. 39 , Para 6.19

[7] Chartered Society of Physiotherapy (2004). Prescribing Rights for Physiotherapists - an update August 2004, page 11, www.csp.org.uk. Accessed on 10th January 2014

[8] MHRA ((Medicines and Healthcare Products Regulatory Agency), (2013). In scope of supplementary prescribers, www.mhra.gov.uk

[9] Onigbinde A.T, Adedoyin R.A, Johnson O.E (2006): Effect of physical therapy interventions on pharmacokinetic variables: A preliminary review, Nigerian Journal of Medical Rehabilitation; Vol. 11.1

[10] Enabulele Osahon (2013). One doctor to 6400 patients in Nigeria. A Business Day Media Ltd. www.businessdayonline.com. Accessed on $16^{\text {th }}$ June 2014.

[11] Australian Medical Association (2012). AMA takes strong stance on non-medical prescribing. Available through:https://ama.com.au/media/ama-takes-strong-stancenon-medicalprescribing. Accessed 29 August, 2013.

[12] Onigbinde et al (2013). Onigbinde Ayodele Teslim, Adereni Adebiyi Solomon, Bamitale Kayode D.S, Kambalametore SVK, M'kumbuzi Vyvienne, Margaret Wazakili (2013). Changing the prescription status of Physiotherapists: Perception of Nigerian physiotherapists. NigerianJournal of Medical Rehabilitation Vol. 16, No 2, Available at http://www.njmr.org.ng. Accessed on $17^{\text {th }}$ June 2014.

[13] Crown Report (1999). Review of prescribing, supply and administration of medicines. http://www.webarchive.nationalarchives.gov.uk/20130107105 354/http:/www.

dh.gov.uk/prod_consum_dh/groups/dh_digitalassets/@dh/@e n/documents/digital asset/dh_4077153.pdf $>$. Accessed 28 August, 2013.

[14] Moore RA, Tramer MR, Carroll D, Wiffen PJ and McQuay HJ (1998). Quantitative systematic review of topically applied non-steroidal anti-inflammatory drugs. British Medical Journal Vol.316: Pgs.333-338

[15] Grimmer et al (2012) Grimmer K, Kumar S and Gilbert A et al (2002): Non-Steroidal Anti-Inflammatory Drugs (NSAIDS). Physiotherapists' use, knowledge and attitudes: Australian journal of physiotherapy; Vol.48. Pgs 82-91

[16] Lansbury and Sullivan (2002): Advising clients about prescription and medications; a survey of physiotherapeutic practice. Australian Journal of Physiotherapy. 88, No 1, Pgs. $18-24$

[17] Chartered Society of Physiotherapy (2013). Practice guidance for physiotherapist supplementary and/or independent prescribers in the safe use of medicines. ( $2^{\text {nd }}$ Edition). www.csp.org.uk/.../csp../csppd026_practice_guidance_prescribers. Accessed $29^{\text {th }}$ August, 2013.s 